\title{
CONTROLLING POWER FLOW LOSSES IN UPFC SYSTEM USING ADAPTIVE NEURO-FUZZY CONTROLLER
}

\author{
P. Hari Krishnan ${ }^{1}$, P.J.Ragu ${ }^{2}$ \\ ${ }^{I}$ Assistant Professor, Department of EEE, Anna University Regional Centre - Coimbatore, Tamil Nadu, India \\ ${ }^{2} P G$ Scholar, Department of C\&I, Anna University Regional Centre - Coimbatore, Tamil Nadu, India
}

\begin{abstract}
The Power disturbances in the transmission line are to be controlled and reduced by using UPFC. Unified Power Flow Controller were the complex power electronic equipment for the control and optimization of power flow in electrical power transmission system in transmission lines. In this project, controlling the power flow and reducing the power oscillation damping losses (Reactive power) flow through a transmission lines with the use of UPFC. Adaptive Neuro-fuzzy controllers were used to control the UPFC system. The Adaptive Neuro-fuzzy controllers were used to generate the pulse signal. The pulse width modulation is used in the Neuro-fuzzy controller to produce the sinusoidal pulse signal. Designing the simulation using MATLAB Simulink is done and the controller of the UPFC is studied. In the UPFC system in transmission lines can be controlling the parameters using control systems, it is observed that whenever the source some real power into the transmission lines it is manifested as a voltage drop across the DC link. Reactive power demand is indicated in the bus bar AC voltage transmission lines. The fall of the DC link voltage is an indication of real power demand from the receiving end. Similarly a fall of the bus bar AC voltage is an indication of Reactive power demand from the receiving end. Simpower system toolbox is used in this works in the control of voltage and Power transfer.
\end{abstract}

Key Words: Adaptive Neuro-Fuzzy controller, UPFC, Pulse Width Modulation. ***.

\section{INTRODUCTION}

In any transmission lines, losses can occur and provides instability in the output. These losses can create the disturbances in the transmission lines. UPFC is one of the electrical devices which control the unwanted disturbance loss in the transmission lines. The UPFC has been containing both series transformer and shunt transformer component which are responsible for transferring the power in the system. The power can be expressed in two ways they are real and reactive component of power. The shunt transformer Component and series transformer components in the UPFC are responsible for the exchange of reactive power in the transmission lines independently. The UPFC can provide simultaneous controlling over all basic power system function parameters like bus voltage and exchanges of real and reactive power.

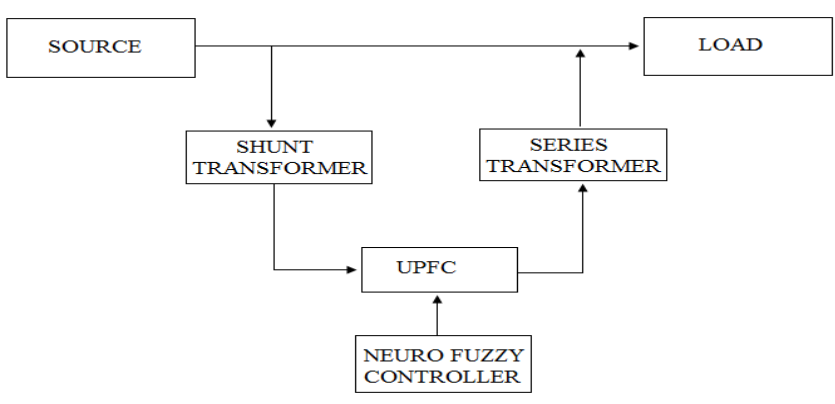

Fig -1: Basic Block Diagram

Even when the controlling is done by the UPFC, which uses two converters namely AC to DC converter and DC to AC converter are connected at the both source and load side of transmission lines, there is a chance of obtaining error at the output. Hence this project aims at controlling UPFC with a Adaptive neuro fuzzy controller which can reduce the harmonic content in the output. The power exchange between the DC link capacitor and load of UPFC can be coordinated using the Adaptive neuro fuzzy controller. By appropriately maintaining the voltage difference between the inverter and the bus bar terminals, the direction of reactive power flow can be controlled. Thus the transient stability of the system can be improved. 
The use of Adaptive Neuro-fuzzy controller with the UPFC can decrease the error component in the output.

\section{DQ THEORY}

The DQ Theory is used to develop a controller that can be used to control the real and reactive power components independently. A three phase system as a whole can source real and reactive power components to a load. The three phase voltage and current in a time varying fashion contribute for the instantaneous real and reactive power in transmission. The rule matrixes are used to given the possible output.

\section{UPFC}

UPFC can be used to controlling the power in transmission lines and increasing the function performance of the system. It is the major role of operation and control of power in the transmission lines. UPFC is the flexible and complex powerful device; the parameters in the transmission lines can be controlled by UPFC system. It is used to control the real and reactive power in transmission lines. In UPFC system contain two components namely series transformer and shunt transformer component they are connected to the converters and inverters.

The encompassing capabilities of voltage regulation, series compensation and phase shifting angle, it can be control both real and reactive power flow in a transmission lines. A shunt transformer and series transformer connected that can be control the various electrical parameters. UPFC consist of two converters they are converter 1 and converter 2 . Converter 1 act as a $\mathrm{AC}$ to $\mathrm{DC}$ converter and converter 2 act as a DC to $\mathrm{AC}$ like as a inverter which are connected through a common DC link capacitor. DC link connected in between the two converters, the voltage can be at any angle with respects to line current.

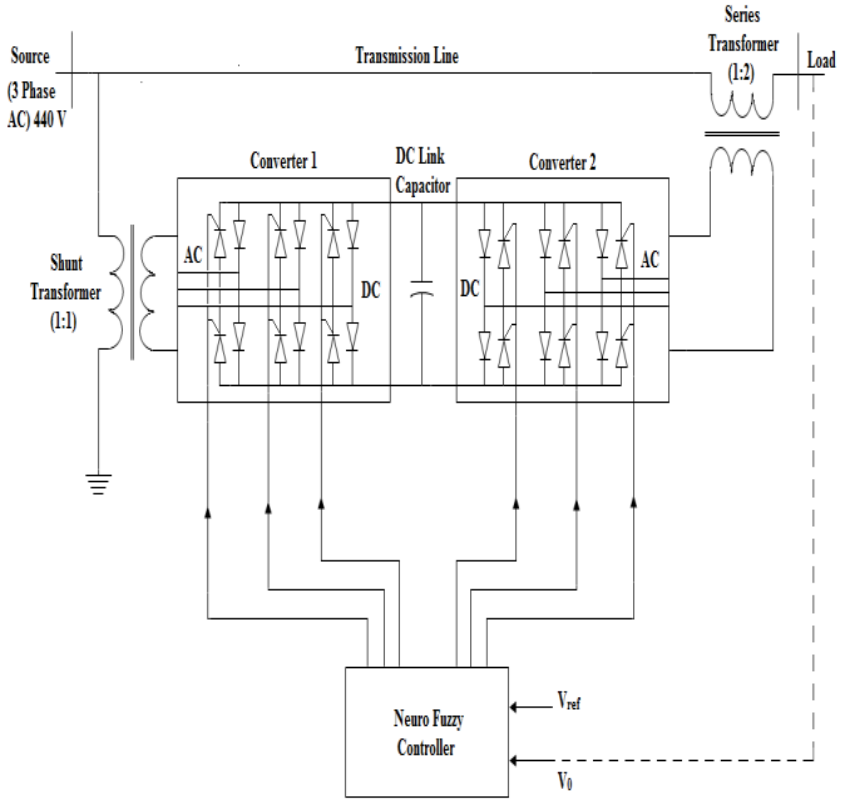

Fig -2: Block Diagram of Three Phase Transmission

The phase angle between injected voltage and line current I can be at $\mathrm{O}^{\circ}$ to $360^{\circ}$. The real and reactive power can be expressed as

$$
\begin{aligned}
& \text { Real power }=\mathrm{V}_{\mathrm{dq}} \cdot \mathrm{I}=\mathrm{V}_{\mathrm{dq}} \mathrm{I} \cos \theta \\
& \text { Reactive power }=\mathrm{V}_{\mathrm{dq}} \cdot \mathrm{I}=\mathrm{V}_{\mathrm{dq}} \mathrm{I} \sin \theta
\end{aligned}
$$

The reactive current can be controlled by regulating the voltage.

The UPFC equipment comprises two identical MOSFET based converters. Each converter includes multiple high power GTO valve structure feeding at intermediate (low voltage) transformer. The converter output is a phase voltage set of sinusoidal to the transmission lines by the three winding main couple transformer. UPFC can be controlled by following functions they are voltage regulation, series reactive compensation, phase angle regulation, simultaneous control of voltage series reactance and phase angle. UPFC can be operating in shunt and series inverter modes.

\section{CONTROLLING WITH UPFC}

In UPFC system the controller are used to control the real and reactive power in UPFC. If the efficiency of the transmission at the load is low then the feedback is given to the controller and the pulses are generated to compensate the loss in UPFC system.

The Neuro fuzzy controller has been combined for the control of the UPFC. With reference MATLAB SIMULINK model it is seen that the two converters namely shunt and series with 
respect to the power transmission lines. The output signal is used to control the reference used PWM generated with the shunt and series.

\section{PULSE WITH MODULATION}

We are using Sinusoidal Pulse Width Modulation (sin PWM) to reduce the lower order harmonics can be eliminated or minimized using PWM.

In using Neuro Fuzzy Controller to be generate the sinusoidal Pulse width modulation to given the input of the UPFC system.

Sin pulse width modulation is used for the proposed rectifier. In this method of modulation, several pulses per half cycle are used as in the case of multiple pulse width modulation. To maintaining the width of all pulses the same as in the case of multiple pulse modulation, the width of each pulse is varied proportional to the amplitude of a sin wave evaluated at the centre of the pulse signal. By comparing a sin pulse signal with a triangular waveform of frequency, the gate pulse signals are generated.

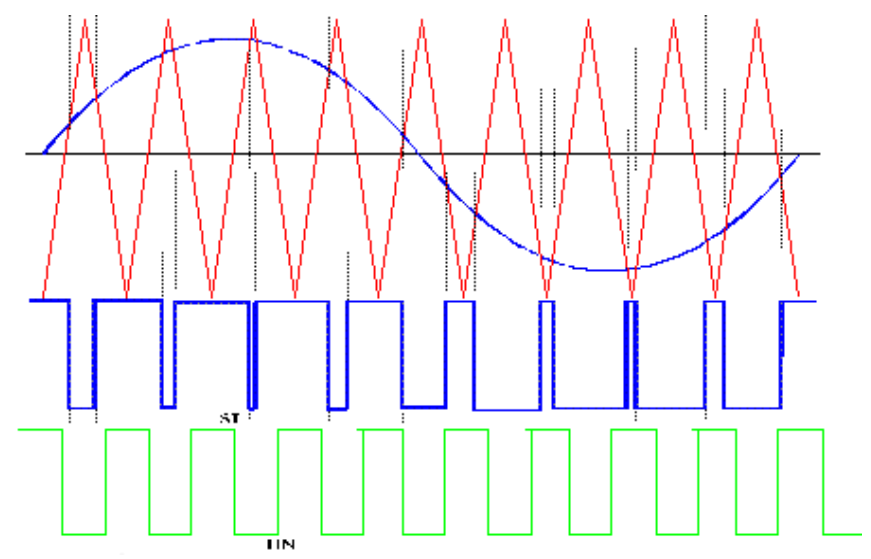

Fig -3: Sine pulse width modulation

\section{NEURO-FUZZY CONTROLLER}

Neuro fuzzy controller is combination of neural network and fuzzy logic controller. Neuro fuzzy is also known as ANFIS (adaptive Neuro fuzzy inference system). In this method is transforming human knowledge into rule base fuzzy logic interface system. The input and output of the size, type and parameter are assigned in trial and error.

To maintain good dynamic response at various operating conditions with the possible choices of UPFC control signal, the controller gains need to be based on system conditions. An adaptive neuro fuzzy inference system has been used in this work to adapt the controller gains of UPFC damping controller.
The following process involving the passage from classical fuzzy logic to the Neuro-adaptive learning approach is briefly presented here.

- Initializing the fuzzy structure.

- Training the initial fuzzy structure for updating the fuzzy parameters to meet the desired control performance.

- Performance of the Neuro fuzzy controller under different operating functions.

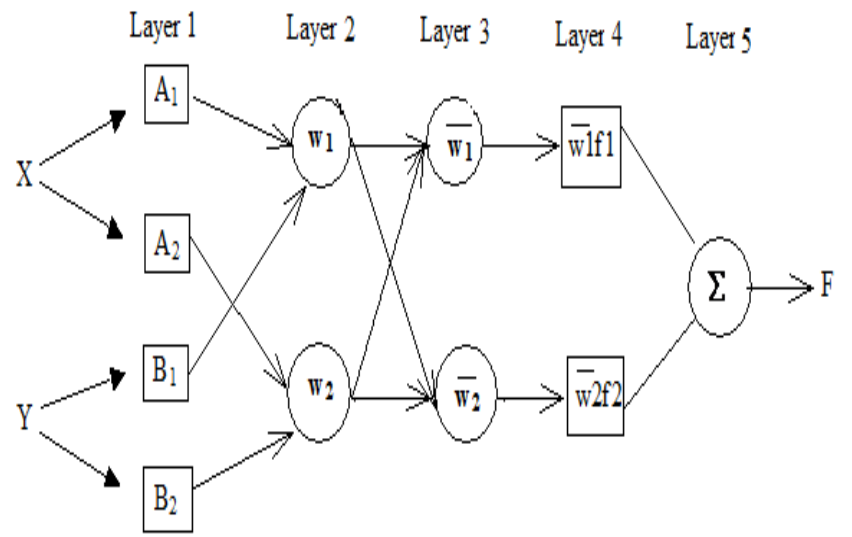

Fig -4: ANFIS architecture

The ANFIS is the abbreviated of adaptive Neuro-fuzzy inference system. In both neural network and Fuzzy logic controller, the input pass through the input layer (by input membership function) and the output could be seen in output layer (by output membership functions). Using a given input/output data set, the toolbox function ANFIS construct a fuzzy inference system (FIS) whose membership function parameters are tuned (adjusted).This adjustment allows your fuzzy systems to learn from the data they are modeling. Rule structure is essentially predetermined by the users' interpretation of the characteristic of the variables in the model.

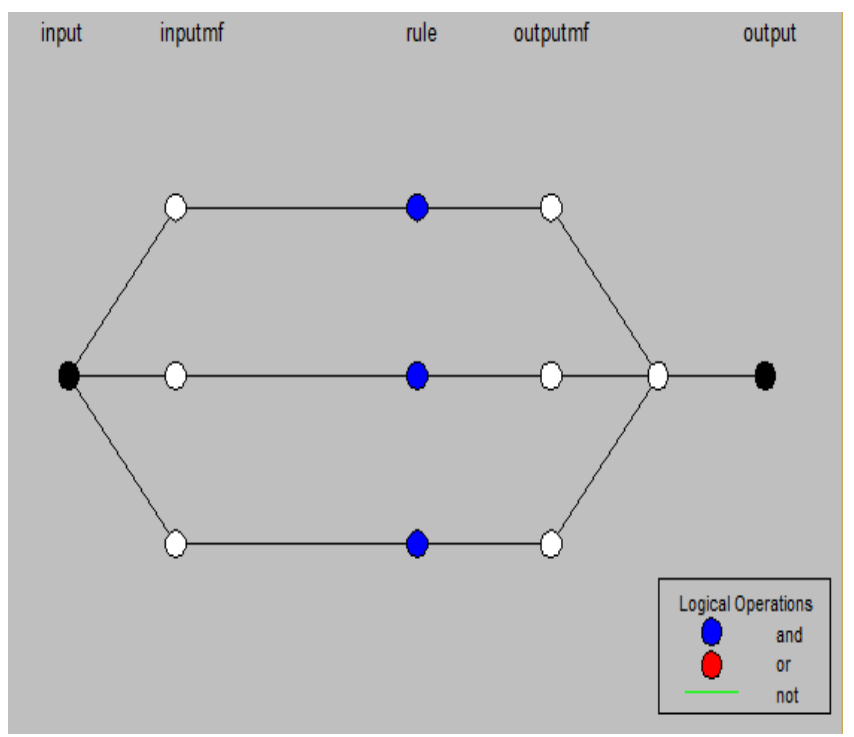


Fig -5: Structure of ANFIS

ANFIS applies FIS technique to data modeling. We can choose membership function parameters automatically using ANFIS tool in MATLAB. Using ANFIS we can apply fuzzy inference to a system for which we already have a collection of input/ output data sets of parameters .Gradient vector reduce some error measures. This error measures is usually defined by the sum of the squared difference between the actual and desired outputs. Collect input/output data in a form that will be usable by ANFIS for training. GUI includes four distinct areas to support a typical work flow (1)Loading ,plotting and clearing data (2)Generating or loading the initial FIS structure (3) training the FIS.(4)Validating the trained FIS.

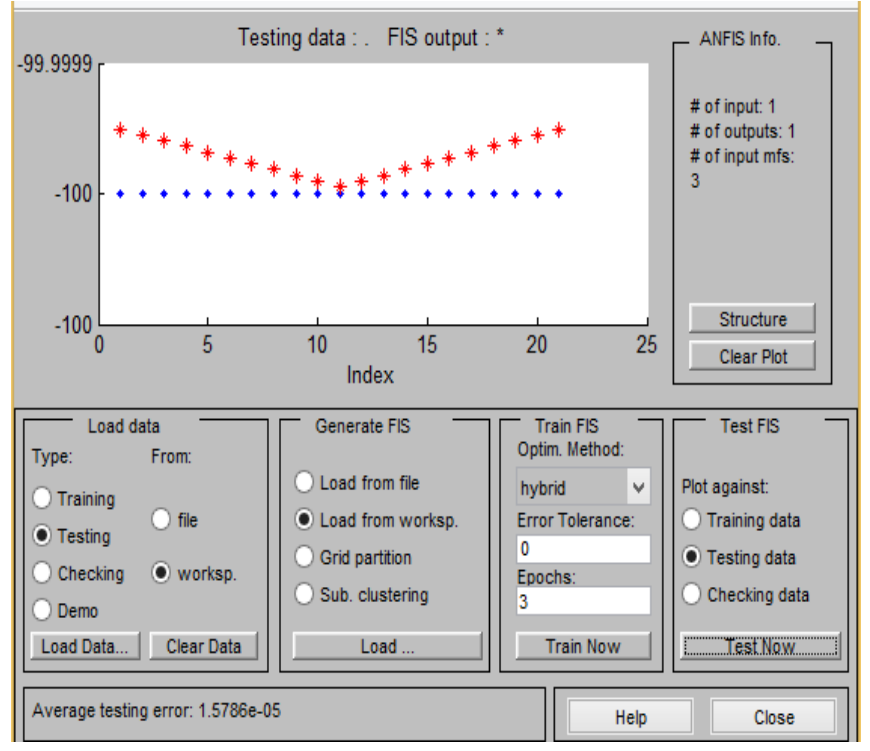

Fig -6: ANFIS Editor Block in MATLAB

\section{RESULTS}

The power loss in the transmission lines is minimized using Adaptive Neuro-fuzzy controller by controlling the UPFC. The figures below show the input, load output, Real and Reactive waveforms.

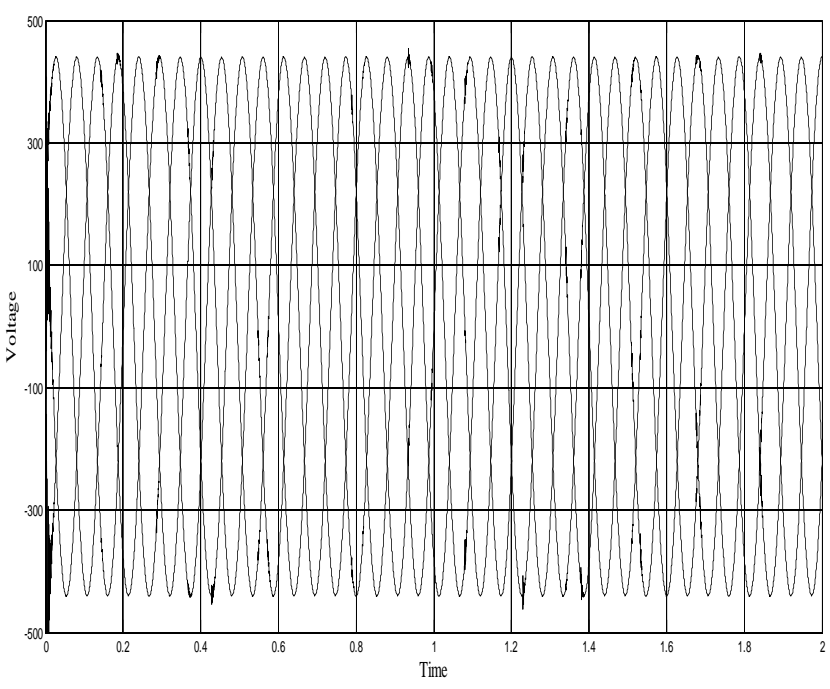

Fig -7: Input Waveform

The input supply is given as $440 \mathrm{~V}, 3 \varphi, 50 \mathrm{~Hz}$ waveform having an rms voltage value of $311.127 \mathrm{~V}$ from a three phase transmission source. The input waveform graph shows the input voltage of 440V as shown in Fig 7.

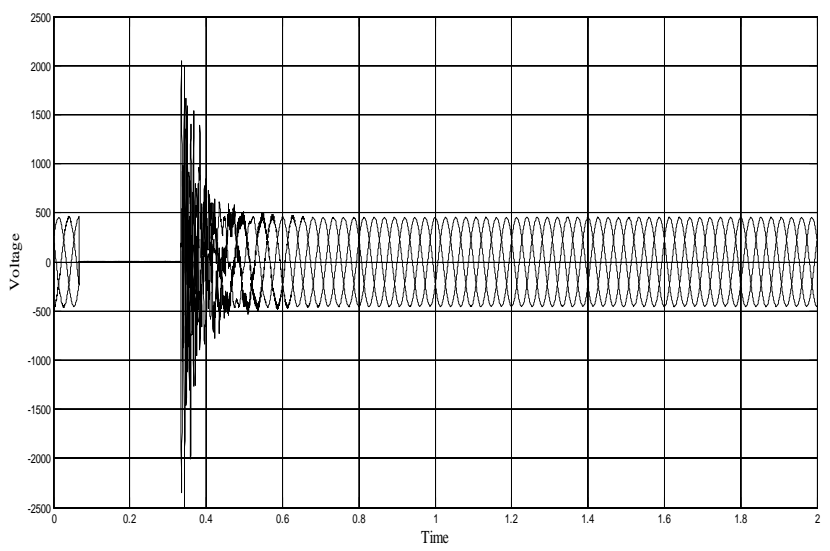

Fig -8: Load Output Waveform

The reference voltage of $500 \mathrm{~V}$ is compared with the UPFC output voltage and the error obtained is controlled by using Neuro-fuzzy controller. The disturbance occurring in the transmission lines is controlled in UPFC thereby generating sinusoidal PWM. This will compensate the error in the transmission lines. The waveform shown in Fig 8, the rectified load output is observed. The losses generated will be corrected by using UPFC system. The output will be in the form of sinusoidal wave. 


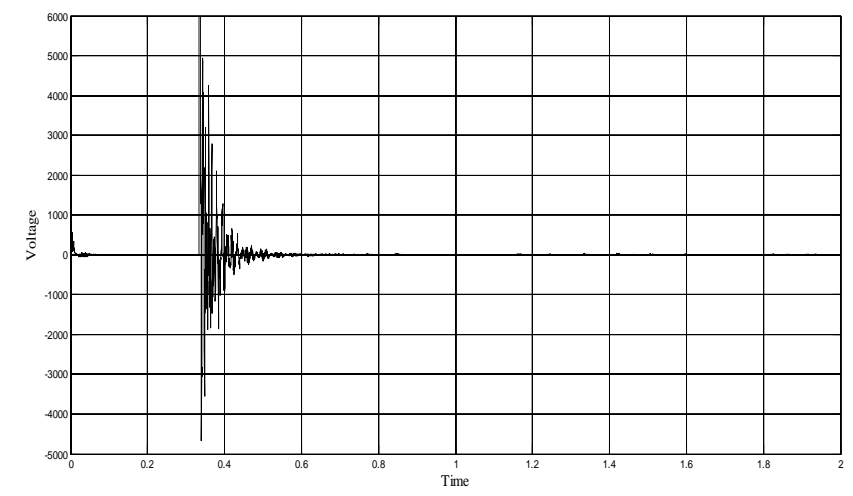

Fig -9: Real Power Waveform

The power in the transmission lines can be represented as real power. Losses will be occurred in the power and as a result the losses will occur in real power as shown in fig.9, using controller to controller the losses in the transmission lines to stable the real power in the transmission lines.

The power in the transmission lines can be represented as reactive power. Losses will be occurred in the power and as a result the losses will occur in reactive power as shown in fig.10, using controller to controller the losses in the transmission lines to stable the real power in the transmission lines.

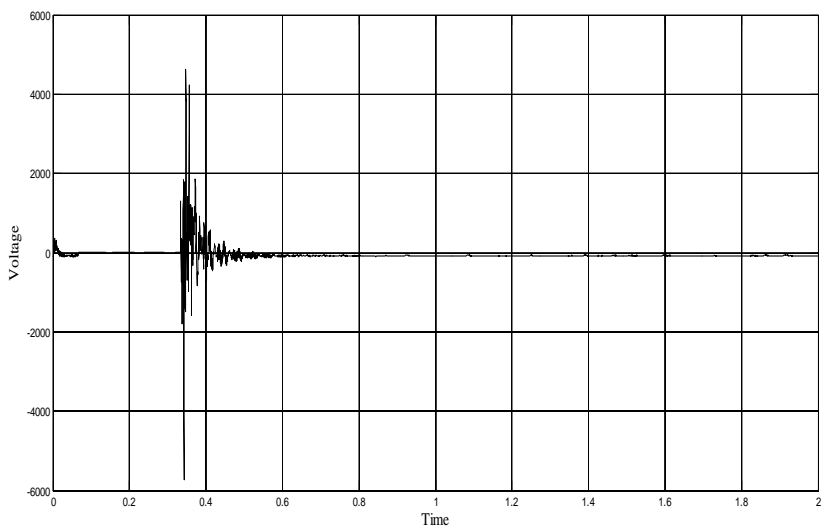

Fig -10: Reactive Power Waveform

The stable output waveform can be seen in real and reactive waveform after the losses has occurred.

Simulation result for using Neuro-fuzzy controller are given the input $440 \mathrm{~V}$ to three phase $\mathrm{AC}$ transmission source the Adaptive Neuro-fuzzy controller generate the PWM to UPFC. The UPFC are used to reduce the reactive power (convert to real power) and generate output waveform. In UPFC signals are given to the load and the load output waveform are generated. The Real \& Reactive waveforms are generated.
Using Adaptive Neuro-fuzzy controller TOTAL HARMONIC DETECTION is reduced up to 12 to $18 \%$ in the waveform.

\section{CONCLUSIONS}

In this paper the power oscillation damping losses and power flow control is reduced in three phase AC transmission by using UPFC. The Adaptive Neuro fuzzy controllers are used to control the UPFC system. The controller (Adaptive Neuro fuzzy controllers) is used to reduce the harmonics and controlling the power flow in the transmission lines signal. The output of harmonics is obtained up to 12 to $18 \%$ in the transmission lines signal waveforms. The harmonics will be reduced and power flow losses will be controlled in the signal frequency by using Adaptive Neuro-fuzzy controller in the UPFC system in AC transmission lines. The simulation results are obtain and analyzed.

\section{ACKNOWLEDGEMENTS}

I would like to record my special thanks and deep sense of indebtedness and hearted gratitude to my gifted guide Mr. P. HARI KRISHNAN, M.E., Assistant Professor, Anna University, Regional Centre Coimbatore, for his active involvement, encouraging, caretaking and valuable suggestions in all way and guiding me in my project. I express my heartfelt thanks to Management and Faculty Members of EEE Department, Anna University, Regional Centre Coimbatore, for her encouragement in this project.

I also extend my sincere thanks to my parents and entire friends to encourage and who have render their valuable help in this project.

\section{REFERENCES}

[1]. V. K. Sood, "HVDC and FACTS Controllers," Kluwer Academic Publishers, 2004, ISBN 1-4020-7890-0.

[2]. Fast-Converging Blind Adaptive Channel-Shortening and Frequency-Domain Equalization Richard K. Martin, Member, IEEE.IEEE TRANSACTIONS ON SIGNAL PROCESSING, VOL. 55, NO. 1, JANUARY 2007.

[3]. Yao Liangzhong, "Neural Networks for Pattern Recognition ", John Wiley \& Sons Inc., 1993.

[4]. L. Gyugyi, C.D. Schauder, S.L. Williams, T.R.Rietman, D.R.Torgerson, A. Edris, "The Unified Power Flow Controller: A New Approach to Power Transmission Control", IEEE Trans., Vol. PWRD-10,No. 2, pp. 1085-1097, April 1995.

[5]. Unit Commitment by an Enhanced Simulated Annealing Algorithm Dimitris N. Simopoulos, Student Member, IEEE, Stavroula D. Kavatza, and Costas D. Vournas, Fellow, IEEE. IEEE TRANSACTIONS ON POWER SYSTEMS, VOL. 21, NO. 1, FEBRUARY 2006.

[6]. K. R. Padiyar and A. M. Kulkarni, "Control design and simulation of unified power flow controller," IEEE Trans. on Power Delivery, vol. 13, no. 4, pp. 1348-1354, 1998. 
[7]. L. Gyugyi, C. D. Schauder, S. L. Torgerson, and A. Edris, "The unified power flow controller: A new approach to power transmission control," IEEE Trans. On Power Delivery, vol. 10, no. 2, pp. 1088-1097, 1995.

[8]. M. Noroozian, L. Angquist, M. Ghandari, and G. Anderson, "Improving power system dynamics by seriesconnected FACTS devices," IEEE Trans. on Power Delivery, vol. 12, no. 4, pp. 1635-1641, 1997.

[9]. F. Z. Peng, H. Akagi, and A. Nabae, "A new approach to

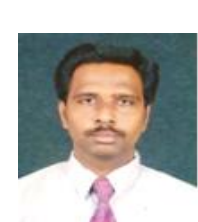

harmonic compensation in power systems-A combined system of shunt passive and series active filters," IEEE Trans. Ind. Applicat., vol. 26, no. 6, pp. 983-990, 1990.

[10]. Edris A-A. Proposed terms and definitions for flexible ac transmission systems (FACTS). IEEE Trans Power Deliv 1997; 2 (4):1848-53.

[11]. D.Ramesh, L.V.Maheshbabu, A UPFC damping control scheme using Lead-Lag and ANN based adaptive controller, IJCTA, Vol 3, Sept-Oct 2012.

[12]. S.Mishra, P.K.Dash and G.Panda, TS-fuzzy controller for UPFC in a multimachine power system, IEEE proc.-

Gener. Transm. Distrib, Vol 147, No 1, January 2000.

[13]. Kalyan K. Sen, Member, IEEE Eric J. Stacey UPFC - Unified Power Flow Controller: Theory, Modeling, and Applications, IEEE Transactions on Power Delivery, Vol. 13, No. 4, October 1998.

[14]. P.Ramesh, Dr.M.D.Damodara Reddy, Loss reduction through optimal placement of Unified Power Flow controller using Friefly Algorithm, IJAREEIE, Vol. 2, Issue 10, October 2013.

[15]. CH. Chengaiah, R.V.S.Satyanarayan, and G.V.Marutheswar, Study on effect of UPFC device in electrical transmission system: power flow assessment, IJEEE, Vol 1, Iss -4, 2012.

[16]. V.Rangavalli, K.Trinadhbabu, Power flow control in HVDC- Link using fuzzy logic controller, IJERA, Vol. 2, Issue 4, July-August 2012.

\section{BIOGRAPHIES}

Hari Krishnan. P Was born in Madras (now Chennai). He received his BE degree in Electrical and Electronics of Madras University in 1997. Received his ME degree in Applied Electronics from Anna University in 2005. He is a Life member of MISTE.He is working as an assistant professor at Anna University- Regional Centre, Coimbatore and pursuing his research programme in the Anna University. His areas of interests include Image processing, Digital signal processing and pattern recogonition.

P.J.Ragu was born in Erode, India. He received his B.E degree in Department of Electronics and Instrumentation Engineering from Anna University - Chennai in 2012. He is pursuing M.E degree in the Department of Control and Instrumentation engineering from Anna University - Chennai. 